\title{
Four Reasons Why Assisted Dying Should Not Be Offered For Depression
}

Thomas Blikshavn, Tonje Lossius Husum \& Morten Magelssen

Post-print version of article published in Journal of Bioethical Inquiry, 14(1): 151-7.

\begin{abstract}
Recently, several authors have argued that assisted dying may be ethically appropriate when requested by a person who suffers from serious depression unresponsive to treatment. We here present four arguments to the contrary. First, the arguments made by proponents of assisted dying rely on notions of "treatment-resistant depression" that are problematic. Second, an individual patient suffering from depression may not be justified in believing that chances of recovery are minimal. Third, the therapeutic significance of hope must be acknowledged; when mental health care opens up the door to admitting hopelessness, there is a danger of a self-fulfilling prophecy. Finally, proponents of assisted dying in mental health care overlook the dangers posed to mental health services by the institutionalization of assisted dying.
\end{abstract}

Assisted dying not only for depression, but also for other mental illnesses, is legal in the Netherlands and Belgium. In the Netherlands the number of persons who undergo assisted dying for such diagnoses is moderate, yet has risen sharply: From only a handful of cases in the previous decade to 14 cases in 2012 and 41 in 2014 (Regionale toetsingscommissies euthanasie 2015).

In the international debate such practices are contested. In two recent articles bioethicists have advanced forceful - yet in our view, deficient - arguments in defense of assisted dying for depression. In the first article, Berghmans et al. argue by 
way of an actual case from the Netherlands ("Janet") that hope for recovery is sometimes illusory and that assisted dying may then be morally acceptable (Berghmans et al. 2013). Presumably, the case is chosen specifically in order to make the case for assisted dying for depression. At the time the decision to provide assisted dying was made the patient had suffered from depression for years, all conventional treatment has been attempted without success, and thus the statistical likelihood of improvement was low. According to the authors the patient had an adequate understanding of her disease, the available treatment and the consequences of a request for assisted dying. On this basis she made the choice to die, and the request was handled professionally in the context of a system that does not perceive significant problems with the practice of assisted dying.

In the second article, Schuklenk and van de Vathorst (S\&V) argue that assisted dying may be morally appropriate when requested by a person who suffers from treatment-resistant depression, TRD (Schuklenk and van de Vathorst 2015a). In particular, S\&V argue that accepting assisted dying for patients suffering from chronic somatic conditions commits one to accepting assisted dying in the setting of TRD; they argue that there are no morally decisive differences between these cases.

Both sets of authors claim that the suffering accompanying some mental illnesses such as severe depression may be equally unbearable as suffering from somatic conditions; that some persons with mental illnesses may make a competent and rational choice for suicide; and that a patient suffering from TRD may rightly consider chances of recovery to be minimal, as may the patient's therapist (Berghmans et al. 2013; Schuklenk and van de Vathorst 2015a).

In this article we examine and critique only the latter of these claims, thus making four arguments against the practice of assisted dying for depression: We first 
critique the use of the TRD construct in the argument for assisted dying. In particular, as TRD is defined by a lack of response to psychopharmacological treatment, potentially effective psychological interventions are overlooked. Second, the nature of psychiatric diagnoses and treatment imply that knowledge of poor prognosis on a group level cannot be transferred to the individual. Third, hope is significant therapeutically and there is a danger of a self-fulfilling prophecy when the therapist gives up hope in the patient's improvement. Fourth, the institutionalization of assisted dying poses dangers to mental health care. These four arguments entail morally decisive differences between depression and somatic conditions. If successful, our counter-arguments therefore undercut a crucial premise in Berghman et al.'s and S\&V's argument for assisted dying in depression and add important reasons why assisted dying should not be offered for this condition.

\section{Antidepressant Non-response and the Concept of TRD}

Some people do stay depressed even after repeated therapeutic attempts. The use of the term TRD, however, adds an aura of objectivity that is hardly justified. No consensus exists on the precise use of the term, and patients may benefit significantly from treatment yet remain classified as having TRD. The crucial point to appreciate is that in the research literature TRD is almost exclusively defined by a lack of symptom response from antidepressant medication. There have been developed several staging systems for depression, none of which are extensively empirically validated, all of which ignore the issue of psychological treatment (McIntyre et al. 2014). The importance of the latter, raising serious concerns about the concept of TRD in the first place, is highlighted by a study of currently depressed patients with at least a two-year history of depression: Following treatment switch after the first treatment failure, a 
non-response to nefazodone did not predict non-response to psychotherapy and vice versa (Schatzberg et al. 2005).

Therefore, when $\mathrm{S} \& \mathrm{~V}$, citing a review that relies on just such a concept of TRD (Souery et al. 2006), state that 20-33 percent of depressed patients are treatmentresistant, they misrepresent the actual clinical problem. They thereby give the false impression that there exists empirical data to support a general notion of treatment futility, applicable to individual cases. Berghmans et al., although not invoking the term TRD, commit the same error when they convey with approval the consultant's diagnosis in Janet's case as one of "interminable suffering due to a serious, chronic and therapy resistant depressive disorder without hope of recovery" (Berghmans et al. 2013; our emphasis). While it is true in general that subsequent trials of antidepressants after first treatment failure generally carry an increased risk of nonresponse or nonremission, the evidence regarding clinical predictors of this subsequent nonresponse amounts at best to weak associations based on low levels of evidence (De Carlo et al. 2016). The same holds for predictors of treatment response in general, where there is a lack of consistent findings, replicable across studies (Dunlop 2015).

TRD, then, is in the current literature not a clinical term, but a technical term pertaining to psychopharmacological interventions, applied in retrospect. Crucially, it does not answer the clinically relevant question of whether there is still hope for getting well. Moreover, a prospective use, meaning "untreatable depression", is currently precluded by the absence of a valid and reliable way of identifying such patients (assuming that it is a valid concept in the first place). Therefore, when S\&V after quoting a patient's account of the phenomenology of being depressed - state that "Imagine what suffering from TRD must be like, knowing that this state will never 
end", this is not merely a clear case of argumentum ad passiones, it is also an inappropriate use of an unfortunate technical term to make unjustified clinical conclusions. Ironically, this belief that the symptoms of depression will never end, would in cognitive-behavioural therapy, a promising approach for TRD (Wiles et al. 2013), be viewed as a symptom as well as a maintaining factor; in treatment, modifying this central belief would be a crucial therapeutic goal.

\section{Diagnostic Categories, Psychiatric Treatment, and Prognosis}

Mental disorders, including depression, are in current diagnostic classification systems quite simply descriptions of behaviour. A psychiatric diagnosis is strictly about "what" not about "why", and a particular diagnosis does not imply a particular etiology (Tsou 2015). In the case of depression, there is substantial evidence that this diagnostic category in reality is highly heterogenous (Fried 2015). The assumption that symptoms are caused by an underlying singular and discrete disease entity is unsupported by evidence. While psychosocial adversities, such as being bullied in adolescence, are clearly related to adult depression (Bowes et al. 2015), they are not part of the diagnostic criteria. Yet, in the treatment of a particular patient, this information may be crucial for understanding and therapy. The consequence of this purely descriptive approach is that diagnostic categories are bound to include patients with vastly different etiology and maintenance factors that underlie the current symptoms and behaviour (Kendell and Jablensky 2003). Related to this, in clinical practice the actual agreement between clinicians in particular cases regarding a diagnosis of depression is remarkably low (Regier et al. 2013). The case related by Berghmans et al. is streamlined in that all such specific details of the patient's story that could be relevant to present alternative, constructive solutions, are lacking. The 
purpose of presenting the case history appears not to give the reader an understanding of the patient, but rather to describe how the patient fits into the Dutch norm for assisted dying.

Therefore, while it is an established fact that patients may complete several antidepressant treatment protocols and stay depressed, the group level concept of treatment resistance, however defined, is of little value on the level of the individual in the absence of an understanding of the individual underlying dynamics. Furthermore, treatments work in a context: Time to relapse after inpatient treatment for longstanding TRD was markedly better when good social support was present (Fedaku 2012). Response rates for adolescent TRD were higher if treatment ended during summer vacation (Shamseddeen et al. 2011). Knowing that a patient has been in treatment and is still depressed conveys little information about whether there is still reasonable hope. In sum, this means that neither therapist nor patient can be justified in concluding from the empirical studies on TRD that this particular patient will not or cannot recover.

Mental diagnoses, then, are in this respect unlike most somatic diagnoses, such as cancer or amyotrophic lateral sclerosis, where one in addition to the purely statistical prediction of prognosis may actually be able to identify and characterize the pathophysiological mechanism that inexorably produces deterioration. In contrast, for a mental illness a prediction of prognosis can be made from a basis of statistics only. This implies neglecting the symptom-producing mechanisms, attention to which may be key to recovery. Assuming that this particular patient, fulfilling any of the current sets of TRD-criteria, is exceedingly unlikely to recover, therefore amounts to an unjustified generalization to the individual from an actuarial risk assessment. 
Stories of hopeless battles won are not rare among clinicians, and permanent remission of depression is described in well-documented case studies even up to 29 years of unremitted depressive symptoms (Brådvik and Crona 2009). On the group level, a study documented increasing rates of recovery from chronic depression for the entire follow-up period of ten years (Mueller et al. 1996). These findings are extended by a long-term follow-up study of inpatients with an initial diagnosis of major depression with melancholic or psychotic features 38-53 years after the index episode. This demonstrated that although the outcome is variable, long-term remission is possible even after an initial severe and chronic clinical course with several depressive episodes (Crona and Brådvik 2012). In retrospect, patients often credit factors outside of healthcare or treatment as decisive for reaching the turningpoint of improvement (Kogstad et al. 2011). Such factors can be, for instance, interpersonal relationships, significant life events or receiving help with work, housing and financial matters.

Moreover, treatment in mental health care is not simply a matter of administering the technology of treatment techniques to the patient. The patient is not only receiving treatment, but is also an active participant contributing to outcome. This seems, unsurprisingly, to hold for all treatment modalities as evidenced by the fact that the therapeutic alliance has an effect on not only outcome in psychotherapy for depression, but also in the case of antidepressant treatment and even pill placebo (Krupnick et al. 1996). The consequence of this is that even in the case of seemingly purely biological interventions like antidepressants, there may be psychological reasons why the patient does not respond. There should be no expectation that these reasons are rational; indeed, a large part of the field of clinical psychology is all about the irrational and emotional aspects of the interaction between patient and therapist. 
Taking this into account, it has been argued from a psychodynamic perspective that treatment resistance will often be accounted for by the therapist stance, or by aspects of the treatment itself, rather than patient factors (Plakun 2006). In the encounter with a clinically depressed patient, attention to this is an integral part of treatment. It is also relevant in understanding how decision-making capacity in this particular group may be impaired not because of deficient understanding and logical processing of information, but due to an illness-related lack of appreciation of how this information applies to one's own situation (Hindmarch et al. 2013). From a clinical point of view, it is fairly obvious that this understanding is relevant also for requests for assisted suicide. Both treatment resistance, and the communication of a death wish, are also events with an interpersonal meaning, and entail an uncommunicated and unconscious expectation of a response that evidently is related to the psychological functioning of the person in question. Attention to the underlying dynamics thus revealed may be key to recovery, in particular in chronic cases (Plakun 2012). In support of this, a recent meta-analysis found large effect sizes on both symptom-oriented measures and psychosocial functioning for long-term psychodynamic psychotherapy for patients with chronic anxiety and depression and high levels of comorbidity (Leichsenring and Rabung 2008). In short, the patient's request that one metaphorically be his executioner is, from this point of view, a precious treatment opportunity that should not be - literally - wasted.

\section{The Therapeutic Significance of Hope}

In a study of 21 survivors of suicide attempts, many survivors stated that the act was triggered by a wish for another life and not by a wish to end it (Vevatne 2006). They often described a longing for close and reciprocal relationships. Other research 
suggests that two of the main reasons for wanting to take one's life is a perception of being a burden on relatives and society and a lack of meaningful relationships (Joiner 2010). In this perspective, accepting the patient's wish to die would be nontherapeutic. Instead of accepting the patient's distorted thoughts about the situation, the therapist could work therapeutically with these assumptions trying to improve the person's quality of life and perception thereof (Joiner 2010).

Hope has long been considered one of the most important factors in all treatment attempts (Miller 1985). Many of the "new" orientations in mental health care such as Recovery, Empowerment and Dialogical/Network traditions consider hope and "expectation of recovery" both as required professional attitudes and as therapeutic interventions in themselves. These attitudes have been shown to be essential among the non-specific factors related to a desirable outcome (Lambert 2013). Having hope on their behalf protects depressive patients from suicide (Smith et al. 2006). Positive expectations also correlate with a positive alliance between therapist and patient (Meyer et al. 2002).

Successful treatment, therefore, is strongly related to these therapist factors. Allying with the patient's death wish, on the other hand, would render the therapeutic relation powerless or even destructive in reinforcing the patient's lack of hope ("even my therapist has given up on me"). S\&V's assurance that the stability of the death wish and the true futility of treatment will become apparent given sufficient time for observation (Schuklenk and van de Vathorst 2015b) misses this point.

Of course, there must be something to hope for. Here is another contrast with somatic diseases: In certain chronic somatic conditions the disease's progress is relentless and inexorable and any hope in recovery might be futile; in chronic 
depression, on the other hand, recovery or at least some relief from emotional pain might be attainable.

Berghmans et al. discuss the possibility that "psychiatric illnesses may take away a realistic perspective on the situation and lead to undue negative feelings, or 'demoralization syndrome"' (Berghmans et al. 2013). They then take the case of Janet to demonstrate that such a demoralization syndrome is not inevitable: For, Janet's assessment of her situation and prospects is realistic and in line with that of her caregivers. However, our main concern is a different one: The therapist's verdict that hope and positive expectations are no longer reasonable may well become a selffulfilling prophecy. One of the main tasks of the therapist is not to accept the person's distorted thoughts and wish to die, but to keep hope when the patient has lost it. The prognosis is uncertain not only because of the nature of psychiatric diagnoses, as discussed above, but also because the likelihood of improvement is dependent on the hope in improvement.

\section{Consequences for Mental Health Services}

Legalizing assisted dying for TRD leads to its institutionalization in mental health care and then likely to its normalization where the practice becomes embedded in the department's routines (Materstvedt 2013). In light of the fundamental importance of hope, emphasized above, one should ask whether the normalization of assisted dying in mental health care might constitute a threat to the services. Mental health care will then go from being an unequivocal bearer of hope always allying with the forces in the patient that strive towards improvement to sometimes giving up on the therapeutic project and acquiescing in the patient's despair. When a socially acceptable way to kill a patient is introduced, there is a danger for therapists to act on the normal, yet 
sometimes intense, negative countertransference that may arise in therapist-patient relationships (Maltsberger and Buie 1974). Therapists may, consciously or unconsciously, influence patients' decisions. One worry is whether mental health professionals will be able to shift between such radically opposed attitudes as kindling hope and admitting hopelessness (Kissane and Kelly 2000); another even graver concern is the signal the normalization of assisted dying sends to all present and future patients in mental health care: that there are situations in which therapists and caregivers will give up hope of your improvement.

The normalization of assisted dying in mental health care would also reinforce the natural tendency to escape from or avoid unwanted mental states ("experiential avoidance"), a common psychological process underlying psychopathology (Hayes et al. 1996). This perspective has received little attention in the literature on assisted dying so far, despite the clinical usefulness of conceptualizing suicidal behavior as dysfunctional problem-solving, generally involving avoidance or escape from aversive emotional states (Chiles and Strosahl 2008). Suicide, and by extension assisted suicide, is from this point of view considered a behaviorally extreme expression of experiential avoidance (Luoma and Villatte 2012). Offering assisted suicide is thus in direct conflict with promoting experiential acceptance, a central part of mindfulness-based interventions like Mindfulness-Based Cognitive Therapy (Segal et al. 2012), Dialectical Behavior Therapy (Linehan 1993), and Acceptance and Commitment Therapy (Hayes et al. 2006). This is problematic, given that interventions based on increasing acceptance (as opposed to symptom change or experiential avoidance) appear to be a promising approach not only in treatment of suicidal behavior in particular, but also in the treatment of several mental and psychosomatic disorders (Pull 2009), including long-standing and recurrent 
depression (Walser et al. 2015; Markanday et al. 2012; Piet and Hougaard 2011; Kenny and Williams 2007). Indeed, the treatment effect appears to be mediated by increases in measures of acceptance and mindfulness (Zettle et al. 2011; Walser et al. 2015). This is consistent with a large and growing literature demonstrating the seemingly paradoxical beneficial effect of acceptance and mindfulness-related processes on outcomes in mental health in general (Ciarrochi et al. 2010).

Our concern, therefore, is how the institutionalization and normalization of assisted dying, through the implicit promotion of non-acceptance and escape from psychological pain, entails a mindset that is part of the very problem it is supposed to solve, and as such generates a context wherein there truly is no hope for persons with severe mental health problems. The empirical literature seems, as shown, quite clear that there exists mental health problems, including cases of depression, that owe their seeming unchangability to the futile attempts to control or change them. Change may thus first happen when the effort is redirected from changing the problem to actively and nonjudgmentally accepting and embracing the pain as a part of life.

A related worry is that when assisted dying for a subset of depressed patients has been normalized, assisted dying will have become an available choice accompanied by a certain way of viewing oneself and one's plight. A wish to die does not arise in an ideological vacuum; the very awareness that therapists may in principle come to give up hope in your eventual improvement may be harmful for the patient's perception of herself.

Considering the emotional pain, avoidance of negative affect, altered cognition, increased recall of negative life events, and failure in role functioning that is part of this disorder, it is not hard to understand how the patient may be drawn towards annihilation rather than growth - doubly so when a socially sanctioned 
alternative is available (Malone et al. 2000). This may be so even when the offer of assisted dying exists outside mental health care itself; the great increase in assisted dying for depression witnessed in recent years in The Netherlands appears to be due to a dedicated clinic offering assisted dying to persons who have been denied this by their regular physicians (including psychiatrists). In sum, then, the very availability of assisted dying may lead some depressed patients to give up the hope that is so vital for therapeutic progress. 


\section{References}

Berghmans, R., Widdershoven, G., \& Widdershoven-Heerding, I. (2013). Physicianassisted suicide in psychiatry and loss of hope. Int J Law Psychiatry, 36(5-6), 436-443.

Bowes, L., Joinson, C., Wolke, D., \& Lewis, G. (2015). Peer victimisation during adolescence and its impact on depression in early adulthood: prospective cohort study in the United Kingdom. BMJ, 350, h2469.

Brådvik, L., \& Crona, L. (2009). Long-lasting recovery in chronic severe depression. Follow-up of two cases, 46 and 50 years after their first admissions for depression. Medical Science Monitor, 10, 31-35.

Chiles, J. A., \& Strosahl, K. D. (2008). Clinical manual for assessment and treatment of suicidal patients: American Psychiatric Association Publishing.

Ciarrochi, J., Bilich, L., \& Godsell, C. (2010). Psychological flexibility as a mechanism of change in acceptance and commitment therapy. In R. A. Baer (Ed.), Assessing mindfulness and acceptance processes in clients: Illuminating the theory and practice of change (pp. 51-75): New Harbinger Publications.

Crona, L., \& Brådvik, L. (2012). Long-term course of severe depression: late remission and recurrence may be found in a follow-up after 38-53 years. Mental Illness, 4(2), e17.

De Carlo, V., Calati, R., \& Serretti, A. (2016). Socio-demographic and clinical predictors of non-response/non-remission in treatment resistant depressed patients: A systematic review. Psychiatry research, 240, 421-430.

Dunlop, B. W. (2015). Prediction of treatment outcomes in major depressive disorder. Expert review of clinical pharmacology, 8(6), 669-672. 
Fried, E. I. (2015). Problematic assumptions have slowed down depression research: why symptoms, not syndromes are the way forward. Frontiers in psychology, $6,309$.

Hayes, S. C., Luoma, J. B., Bond, F. W., Masuda, A., \& Lillis, J. (2006). Acceptance and commitment therapy: Model, processes and outcomes. Behaviour research and therapy, 44(1), 1-25.

Hayes, S. C., Wilson, K. G., Gifford, E. V., Follette, V. M., \& Strosahl, K. (1996). Experiential avoidance and behavioral disorders: a functional dimensional approach to diagnosis and treatment. Journal of Consulting and Clinical Psychology, 64(6), 1152.

Hindmarch, T., Hotopf, M., \& Owen, G. S. (2013). Depression and decision-making capacity for treatment or research: a systematic review. BMC Medical Ethics, $14(1), 54$

Joiner, T. E. (2010). Myths about suicide. Cambridge, Mass.: Harvard University Press.

Kendell, R., \& Jablensky, A. (2003). Distinguishing between the validity and utility of psychiatric diagnoses. American Journal of Psychiatry, 160(1), 4-12.

Kenny, M., \& Williams, J. (2007). Treatment-resistant depressed patients show a good response to mindfulness-based cognitive therapy. Behaviour research and therapy, 45(3), 617-625.

Kissane, D. W., \& Kelly, B. J. (2000). Demoralisation, depression and desire for death: problems with the Dutch guidelines for euthanasia of the mentally ill. Australian and New Zealand Journal of Psychiatry, 34(2), 325-333.

Kogstad, R., Ekeland, T.-J., \& Hummelvoll, J. (2011). In defence of a humanistic approach to mental health care: Recovery processes investigated with the help 
of clients' narratives on turning points and processes of gradual change. Journal of psychiatric and mental health nursing, 18(6), 479-486.

Krupnick, J. L., Sotsky, S. M., Simmens, S., Moyer, J., Elkin, I., Watkins, J., et al. (1996). The role of the therapeutic alliance in psychotherapy and pharmacotherapy outcome: findings in the National Institute of Mental Health Treatment of Depression Collaborative Research Program. Journal of Consulting and Clinical Psychology, 64(3), 532-539.

Lambert, M. J. (2013). Bergin and Garfield's handbook of psychotherapy and behavior change. Hoboken, NJ: John Wiley \& Sons.

Leichsenring, F., \& Rabung, S. (2008). Effectiveness of long-term psychodynamic psychotherapy: A meta-analysis. JAMA, 300(13), 1551-1565.

Linehan, M. (1993). Cognitive-behavioral treatment of borderline personality disorder: Guilford Press.

Luoma, J. B., \& Villatte, J. L. (2012). Mindfulness in the treatment of suicidal individuals. Cognitive and behavioral practice, 19(2), 265-276.

Malone, K. M., Oquendo, M. A., Haas, G. L., Ellis, S. P., Li, S., \& Mann, J. J. (2000). Protective factors against suicidal acts in major depression: reasons for living. American Journal of Psychiatry, 157(7), 1084-1088.

Maltsberger, J. T., \& Buie, D. H. (1974). Countertransference hate in the treatment of suicidal patients. Archives of General Psychiatry, 30(5), 625-633.

Markanday, S., Data-Franco, J., Dyson, L., Murrant, S., Arbuckle, C., McGillvray, J., et al. (2012). Acceptance and commitment therapy for treatment-resistant depression. Australian and New Zealand Journal of Psychiatry, 0004867412446491. 
Materstvedt, L. J. (2013). Palliative care ethics: The problems of combining palliation and assisted dying. Progress in Palliative Care, 21(3), 158-164.

McIntyre, R. S., Filteau, M.-J., Martin, L., Patry, S., Carvalho, A., Cha, D. S., et al. (2014). Treatment-resistant depression: definitions, review of the evidence, and algorithmic approach. Journal of affective disorders, 156, 1-7.

Meyer, B., Pilkonis, P. A., Krupnick, J. L., Egan, M. K., Simmens, S. J., \& Sotsky, S. M. (2002). Treatment expectancies, patient alliance and outcome: Further analyses from the National Institute of Mental Health Treatment of Depression Collaborative Research Program. Journal of Consulting and Clinical Psychology, 70(4), 1051-1055.

Miller, J. F. (1985). Inspiring hope. The American Journal of Nursing, 85(1), 22-28.

Mueller, T. I., Keller, M. B., Leon, A. C., Solomon, D. A., Shea, M. T., Coryell, W., et al. (1996). Recovery after 5 years of unremitting major depressive disorder. Archives of General Psychiatry, 53(9), 794-799.

Piet, J., \& Hougaard, E. (2011). The effect of mindfulness-based cognitive therapy for prevention of relapse in recurrent major depressive disorder: a systematic review and meta-analysis. Clinical Psychology Review, 31(6), 1032-1040.

Plakun, E. (2012). Treatment resistance and psychodynamic psychiatry: Concepts psychiatry needs from psychoanalysis. Psychodynamic psychiatry, 40(2), 183.

Plakun, E. M. (2006). A view from Riggs_-Treatment resistance and patient authority: I. A psychodynamic perspective on treatment resistance. Journal of the American Academy of Psychoanalysis and Dynamic Psychiatry, 34(2), 349-366.

Pull, C. B. (2009). Current empirical status of acceptance and commitment therapy. Current Opinion in Psychiatry, 22(1), 55-60. 
Regier, D. A., Narrow, W. E., Clarke, D. E., Kraemer, H. C., Kuramoto, S. J., Kuhl, E. A., et al. (2013). DSM-5 field trials in the United States and Canada, Part II: test-retest reliability of selected categorical diagnoses. American Journal of Psychiatry.

Regionale toetsingscommissies euthanasie (2015). https://www.euthanasiecommissie.nl. Accessed 23 Jun 2016.

Schatzberg, A. F., Rush, A. J., Arnow, B. A., Banks, P. L., Blalock, J. A., Borian, F. E., et al. (2005). Chronic depression: medication (nefazodone) or psychotherapy (CBASP) is effective when the other is not. Archives of General Psychiatry, 62(5), 513-520.

Schuklenk, U., \& van de Vathorst, S. (2015a). Treatment-resistant major depressive disorder and assisted dying. Journal of Medical Ethics, 41(8), 577-583.

Schuklenk, U., \& van de Vathorst, S. (2015b). Treatment-resistant major depressive disorder and assisted dying: response to comments. Journal of Medical Ethics, 41(8), 589-591.

Segal, Z. V., Williams, J. M. G., \& Teasdale, J. D. (2012). Mindfulness-based cognitive therapy for depression: Guilford Press.

Shamseddeen, W., Clarke, G., Wagner, K. D., Ryan, N. D., Birmaher, B., Emslie, G., et al. (2011). Treatment-resistant depressed youth show a higher response rate if treatment ends during summer school break. Journal of the American Academy of Child \& Adolescent Psychiatry, 50(11), 1140-1148.

Smith, J. M., Alloy, L. B., \& Abramson, L. Y. (2006). Cognitive vulnerability to depression, rumination, hopelessness, and suicidal ideation: multiple pathways to self - injurious thinking. Suicide and Life-threatening behavior, 36(4), 443454. 
Souery, D., Papakostas, G. I., \& Trivedi, M. H. (2006). Treatment-resistant depression. Journal of Clinical Psychiatry, 67(suppl. 6), 16-22.

Tsou, J. Y. (2015). DSM-5 and psychiatry's second revolution: Descriptive vs. theoretical approaches to psychiatric classification. In S. Demazeux \& P. Singy (Eds.), The DSM-5 in Perspective (pp. 43-62): Springer.

Vevatne, K. (2006). Selvmordsforsøket - søken mot livet. University of Bergen, Norway.

Walser, R. D., Garvert, D. W., Karlin, B. E., Trockel, M., Ryu, D. M., \& Taylor, C. B. (2015). Effectiveness of Acceptance and Commitment Therapy in treating depression and suicidal ideation in Veterans. Behaviour research and therapy, 74, 25-31.

Wiles, N., Thomas, L., Abel, A., Ridgway, N., Turner, N., Campbell, J., et al. (2013). Cognitive behavioural therapy as an adjunct to pharmacotherapy for primary care based patients with treatment resistant depression: results of the CoBalT randomised controlled trial. The Lancet, 381(9864), 375-384.

Zettle, R. D., Rains, J. C., \& Hayes, S. C. (2011). Processes of change in acceptance and commitment therapy and cognitive therapy for depression: A mediation reanalysis of Zettle and Rains. Behavior Modification, 35(3), 265-283. 